\title{
Dermatology: a specialty in crisis
}

\author{
Author: David Eedy ${ }^{\mathrm{A}}$
}

Dermatologists in the UK face a massive increase in demand. They treat over 2,000 types of skin conditions in patients of all ages. Each year, $54 \%$ of the population is affected by skin disease, with $23-33 \%$ of the population at any time with a skin disease that would benefit from dermatology care. ${ }^{1}$

The steadily increasing incidence of skin cancer over recent years has completely changed the practice of dermatology. In the UK at least 260,000 skin cancers are treated every year. ${ }^{2}$ Melanoma is the ninth commonest cancer in the UK with $>13,000$ new cases in $2012 .^{3}$ For every melanoma diagnosed, a dermatologist may expect to see 20-40 benign lesions referred from general practitioners (GPs). The tsunami of skin cancer, including much of the surgery for it now undertaken by dermatologists, has transformed the workload of dermatology departments and now accounts for approximately $50 \%$ of their workload. ${ }^{2}$ In addition, dermatologists routinely treat patients with diabetes, HIV, immunosuppression and organ transplantrelated cancers, as well as the skin-related side effects of drugs for these diseases.

There is a stark contrast between the resources required and the resources allocated. Inadequate education in medical schools, insufficient numbers of dermatologists, a lack of standardised mandatory training for GPs and changes in commissioning threaten departments that have taken decades to develop. On average, medical students receive no more than six days training in dermatology in undergraduate training even though a quarter of GP appointments concern the skin. ${ }^{1}$

In a recent House of Lords debate, Lord Prior admitted that there is a deficiency of around 177 dermatologists in England. ${ }^{4}$ The Royal College of Physicians (RCP) recommends one fulltime equivalent (FTE) consultant per 62,500 population. ${ }^{5}$ No single region in Britain has enough consultants to meet this recommendation. For a population of 61.8 million, the RCP recommends 989 FTE consultant dermatologists. In 2012, the British Association of Dermatologists (BAD) found there were 813 dermatology specialists in the UK (consultants, trainees, associates and associate trainees, not all full time) and a total of 729 consultant posts, 75 of which were vacant and 98 were occupied by locums. ${ }^{6}$ Compared to the RCP's recommendations, the BAD figures show a shortfall in the region of 250 consultants. While the solution is simple allocation of further training posts for dermatology - it is not

Author: Apresident, British Association of Dermatologists, London, UK being implemented. In fact, the reverse is occurring - Health Education England has commissioned only 177 specialtytraining places in 2014/15, a reduction from the previous 178 posts. $^{7}$

However, the crisis extends beyond staffing and training. Catastrophic healthcare commissioning decisions are decimating secondary care dermatology, as exemplified by recent events at Nottingham University Hospital (NUH) earlier this year.

Once one of the UK's centres of excellence, Nottingham was one of the largest academic and research centres in addition to providing local and tertiary clinical services. The high-quality publications of this centre were published in the highest impact journals. Yet this cornerstone of dermatology expertise has been all but been obliterated in just a few years. How could this happen?

Following the advent of the National Independent Sector Treatment Centre Programme under the last Labour government, which sought to increase community-based care, outpatient services from NUH were transferred in 2008 to the new Nottingham Treatment Centre run by Circle. Initially, a trust agreement allowed this service to be provided by trust consultants, working shifts in the community centre. However, in 2012, Circle won a tender involving transfer of the NHS contracts of most consultant dermatologists to Circle. In March 2013, the consultants wrote an explicit letter warning that if this transfer went ahead, most of the consultants would leave within a year. ${ }^{8}$

This warning went unheeded and most consultants chose to transfer to other dermatology departments. This was easily foreseen: there are vacant posts in even the most prestigious departments as a result. As Circle became increasingly dependent on locums, both undergraduate and postgraduate training was removed. Consultant shortages mean that, not only is it easy for departing staff to find new jobs, it is difficult to replace them.

The subsequent collapse of this internationally renowned department precipitated an independent investigation which called the process an 'unmitigated disaster'. ${ }^{8}$ The consultants' warnings were deemed justifiable on the basis of concerns about training, research, fracturing of patient care between acute and tertiary services care, and overall sustainability of the service model. ${ }^{8}$ At the time of publication of the inquiry's findings, Circle had only 3.8 WTE consultants, supplemented by six locums. The report stated that a number of these locums were European graduates not automatically eligible for entry onto the GMC Specialist Register and therefore not possessing 
Certificates of Completion of Training, thus making them unqualified to train specialty registrars. Despite this, these

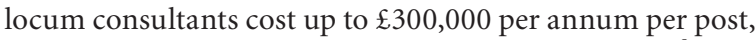
greatly in excess of a standard NHS consultant salary. ${ }^{8}$

Practical problems arose for trust patients. The Circle Treatment Centre only dealt with 'choose and book' cases, leaving a vast university teaching hospital bereft of acute inpatient dermatology care. Circle offers only dermatology advice for inpatients that can be transferred from the ward to the separate outpatient building during office hours. Who looks after the patients in this large specialist university hospital when the Circle Treatment Centre closes its doors at 5pm?

NUH provides specialist paediatric dermatology services to the East Midlands. One consultant is maintaining this service and general paediatric services to Nottingham, supported by an academic colleague one day a week. Children referred from outside Nottingham by GPs or consultants can no longer be seen. Paediatric dermatology is an essential component of the Nottingham Children's Hospital, so relying on a single-handed consultant places the whole NUH tertiary paediatric service on a knife edge.

Nottingham remains with fragmented care pathways for patients requiring specialist care, limited on-call care transfer to Leicester of sick patients arriving in the emergency department or risk of a 'never event' if patients are too sick to transfer, loss of all dermatology trainees and medical students, reduction in research activity and reduced service facilities, and no acute adult dermatology services.

Although the independent investigation didn't point the finger at any one group, it is clear that commissioning groups and private providers across the country can and must learn a great deal from these events.

Private health providers have advanced expertise in preparing bids and presentations which NHS trusts cannot match without the same level of investment or incentive. However, bidding and presentation expertise does not necessarily accurately reflect an ability to run the services. Commissioners need to ensure provider bidders can prove that they can deliver on contracts. In this particular case, Circle's assumption that all clinical staff would be happy to be seconded from the NHS would have been easy to investigate and disprove.

It is a shock that the commissioners were deaf to the concerns of their consultants and the advice of national bodies including the BAD and RCP. Within the wider commissioning process it is clear that clinical commissioning groups (CCGs) and trusts need to be ready to listen to the concerns of their clinical staff, and be quicker to read these signs.

Within dermatology itself, events at Nottingham have highlighted the national issues facing the specialty. Commissioners need to carefully consider the capability of private providers to carry out their contract, including not only staffing levels but compliance with national guidance, education, training and research. The CCG has a duty to comply with the principles of fairness, transparency and non-discrimination. Private providers must be prevented from 'cherry picking' the easiest and most lucrative work at a cost to the NHS.

The issues that plague dermatology in the UK are widespread, but there are solutions. Crucially, the UK needs more consultant dermatologists to reflect the growing demand on dermatology services. There is also a requirement for more thorough dermatology training in the undergraduate curriculum to provide basic dermatology skills throughout the medical workforce. This is particularly important as skin diseases are often comorbidities to other diseases. There is a vital need for further mandatory dermatology training in the GP curriculum. A more able primary care workforce would reduce the pressure on secondary care.

As president of the BAD, I have been fortunate enough to see the great work that my specialty does in the UK, and it is clear that we are widely respected as one of the most advanced countries in the field. The reputation of British dermatology remains extremely high internationally and it would be a tragedy to see this lost.

\section{References}

1 Schofield JK, Grindlay D, Williams HC. Skin conditions in the UK: a health care needs assessment. Nottingham: Centre of Evidence Based Dermatology, University of Nottingham, 2009.

2 Leigh IM. Progress in skin cancer: the UK experience. $\mathrm{Br} J$ Dermatol 2014;171:443-5.

3 Cancer Research UK. Skin cancer statistics. London: Cancer Research UK, 2015. Available online at www.cancerresearchuk.org/ health-professional/cancer-statistics/statistics-by-cancer-type/skincancer [Accessed 29 September 2015].

4 House of Lords. Health: Skin Cancer. Daily Hansard: 22 July 2015, Column 1113. Available online at www.publications.parliament. uk/pa/ld201516/ldhansrd/text/150722-0001.htm\#15072240000327 [Accessed 29 September 2015].

5 Royal College of Physicians. Dermatology. London: RCP, 2013. Available online at www.rcplondon.ac.uk/sites/default/files/ dermatology.pdf [Accessed 29 September 2015].

6 British Association of Dermatologists. Clinical services. London: BAD, 2015. Available online at www.bad.org.uk/healthcareprofessionals/clinical-services/ [Accessed 29 September 2015].

7 Health Education England. Investing in people for health and healthcare: Workforce plan for England, proposed education and training commissions for 2014/15. Leeds: HEE, 2013. Available online at http://hee.nhs.uk/wp-content/uploads/sites/321/2013/12/ Workforce-plan-interactivel.pdf [Accessed 29 September 2015].

8 Clough C, Bowns I, Thome DC, Jones S. Final report - independent review of Nottingham Dermatology Services: 4 June 2015. Available online at www.healthwatchnottinghamshire.co.uk/wp-content/ uploads/2015/06/Final-Report-from-the-Independent-ReviewNottingham-Dermatology-Service.-4-June-2015.pdf [Accessed 29 September 2015].

Address for correspondence: Dr D Eedy, British Association of Dermatologists, Willan House, 4 Fitzroy Square, London W1T 5 HQ, UK.

Email: davidjeedy@gmail.com 